\title{
Prevention of Disasters using Automated Railway Crossing System
}

\author{
Yathish D P, Nandini S
}

\begin{abstract}
Railway is the most prominent and most economical way of transport. Majority of people depend on railways for transportation. Rail modes are most commonly used and very effective mode of commuting and goods carriage over long, short distances. In this paper, we are preparing a system in order to prevent the disasters which happen due to unmanned level crossing in the railways. For this system, Arduino Uno is used as the platform with ATMEGA16U2 as the microcontroller. In order to detect the train as well as the obstacles ultra-sonic sensors are used. When the train approaches the unmanned zone, ultrasonic sensor will detect the arrival of train which is kept 2 KM away from the railway crossing zone. The input of ultrasonic sensor is sent to Arduino Uno to activate the railway gates operated by $D C$ motors. These gates are controlled or driven by motor driver circuit. If any obstacles are detected on the track can also be detected by the ultrasonic sensors which are kept at the gate and it will alert the train, with the help of led signal. Due to this led signal, the train will slow down the speed mechanically or even the train can stop if it's necessary. This system is demonstrated to prevent and stop the disaster at railway crossing zones.
\end{abstract}

Keywords : Arduino Uno, Motor driver, Ultrasonic sensors.

\section{INTRODUCTION}

The total length of Indian railways is $119632 \mathrm{KM}$ or 74330 miles and the track length over a route is of $67312 \mathrm{KM}$. The place or junction where the railways intersect the roads is called as railway crossings. There are about 31847 railway crossing across the country, among these crossing 13531 are unmanned or without any barrier. Due to these 13531 unmanned crossings about $30 \%$ of train disaster occurs [1]. Around $43.5 \%$ of the disasters are due to level crossing and about $3.6 \%$ of the railway disasters are due to fire catch up in trains. $4.7 \%$ of the disaster is due to collisions of the trains and $1.7 \%$ is due to miscellaneous accidents. About $46.5 \%$ accidents are due to derailments. As more than $30 \%$ of disasters are due to unmanned crossings. The main reasons for these disasters are due to unmanned level crossings [1]. In this proposed system we are using Arduino Uno with ATMega16U2 as microcontroller and Ultrasonic sensors to detect the arrival of train and DC motors to operate the opening and closing of railway gates.

Revised Manuscript Received on March 11, 2020.

* Correspondence Author

Mr. Yathish.D.P*, Assistant professor in Computer Science and Engineering Department, GITAM, School of Technology, Bangalore.

Ms. Nandini S, Assistant professor in Computer Science and Engineering Department ,GITAM, School of Technology, Bangalore.

(C) The Authors. Published by Blue Eyes Intelligence Engineering and Sciences Publication (BEIESP). This is an open access article under the CC BY-NC-ND license (http://creativecommons.org/licenses/by-nc-nd/4.0/)
The ultrasonic sensors which are placed 2KM away from the railway gate detects the arrival of the train and sends the trigger to the Arduino which in turn power up the DC motors for the opening and closing of railway gates. If any obstacles are found near the railway gate will be detected by ultrasonic sensor which is placed near the gate and it triggers the Arduino to alert the train with the help of signal lights so that the train will slow down or if necessary it stops. The main causes for these disasters are depicted in figure 1.

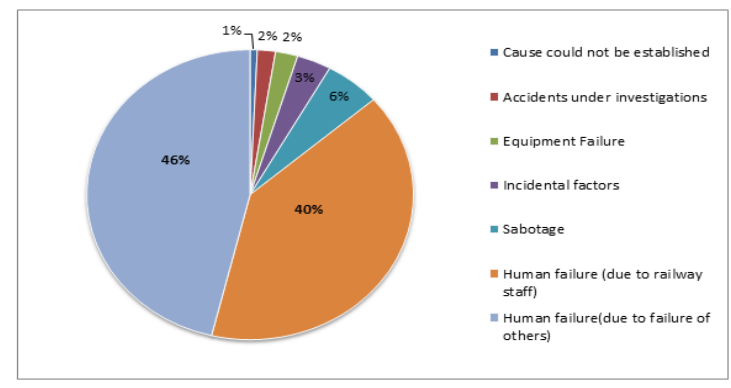

Figure 1: Causes for railway disaster

\section{RELATED WORK}

In [2] the author is attaching the sensors in the train itself which can able to detect the obstacle and send the alert message to the train driver and in turn author is also using GPS as well as GPRS in order to detect the train position to avoid head collisions but the main drawback of this paper is if the obstacle is detected also train cannot slow down its speed with such short distance because the range of the sensors will be too small. In [3] the author is using IR sensors [9] to detect the obstacle, but the main drawback of this paper is placing of the sensors. In this paper author is using the sensors $2 \mathrm{Km}$ away from the gate. In this case the sensors will just going to detect the arrival of the train and if the train arrives near to the sensor it will automatically close the gate, but in this case if any humans or animals or any obstacles present near the gate means they are not detected and the disasters still occurs in this case. In [4] the system has been designed for detecting the train near the gate, if train is detected gates will be closed automatically. The draw back in this paper is the author is placing the sensors near the which can detect the arrival of the train but if the train is travelling too fast means the gate closing time will be very less and it cannot be closed on time which again leads to disasters.

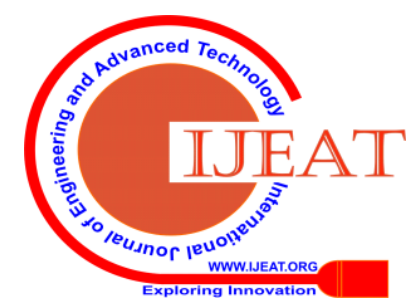




\section{Prevention of Disasters using Automated Railway Crossing System}

In [7] the proposed system concentrates on detecting the train using IR sensors and if any train is detected the gates will be closes automatically. The main drawback of this paper is the author is placing the sensors near the gate. If any large vehicles are there on the crossing means the sensors cannot able to detect the train and in turn results in disasters due to collision. In [8] the author is using IR sensors to detect the arrival of the train. The main disadvantage of this scheme is they are checking only the arrival as train but they are not checking whether any obstacle like human, vehicles or any animals are present on the track before closing the gate.IR sensors [9] which the author is using works well under normal day light but if it is dark the working or the efficiency of the IR sensors will be reduced resulting in degrading of the system performance.

\section{PROPOSED MODEL}

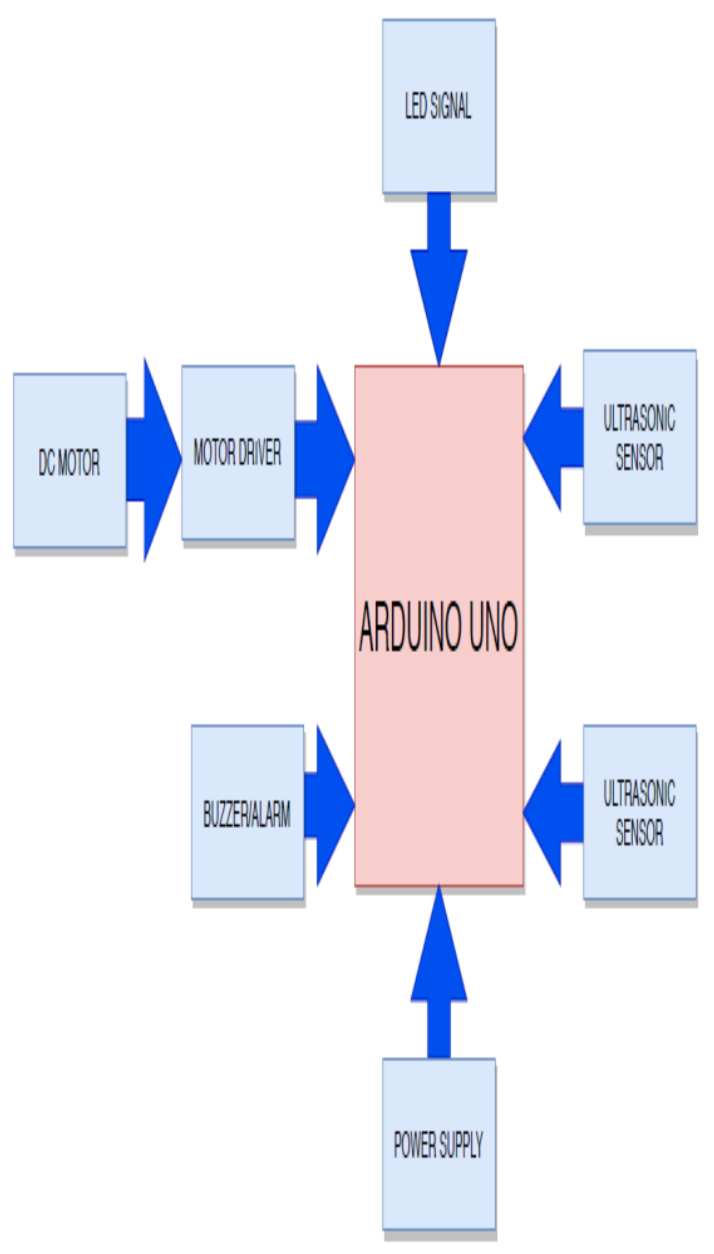

Figure 2: System Architecture

The system architecture shown in figure 2 consists of Arduino Uno [5] with ATMega16U2 as microcontroller which is used to control all the other devices present in the system. The ultrasonic sensor [6] which is placed 2KM away from the railway gate will detect the arrival of the train and sends the trigger to the Arduino Uno [5] which activates the DC motor in order to close the gate in turn it also checks for any obstacle like vehicles or humans near the gate. If any obstacles are present the Arduino will going to alert the train from $2 \mathrm{KM}$ away with the help of LED light so that the train may slow down or if necessary it may even stop. When the train crosses the gate and reaches the second ultra-sonic sensor placed 2KM away from other side of the gate, sensor will trigger the Arduino so that it activates the DC motor again so that the gates will be opened automatically. The operation of the system is shown in figure 3 .

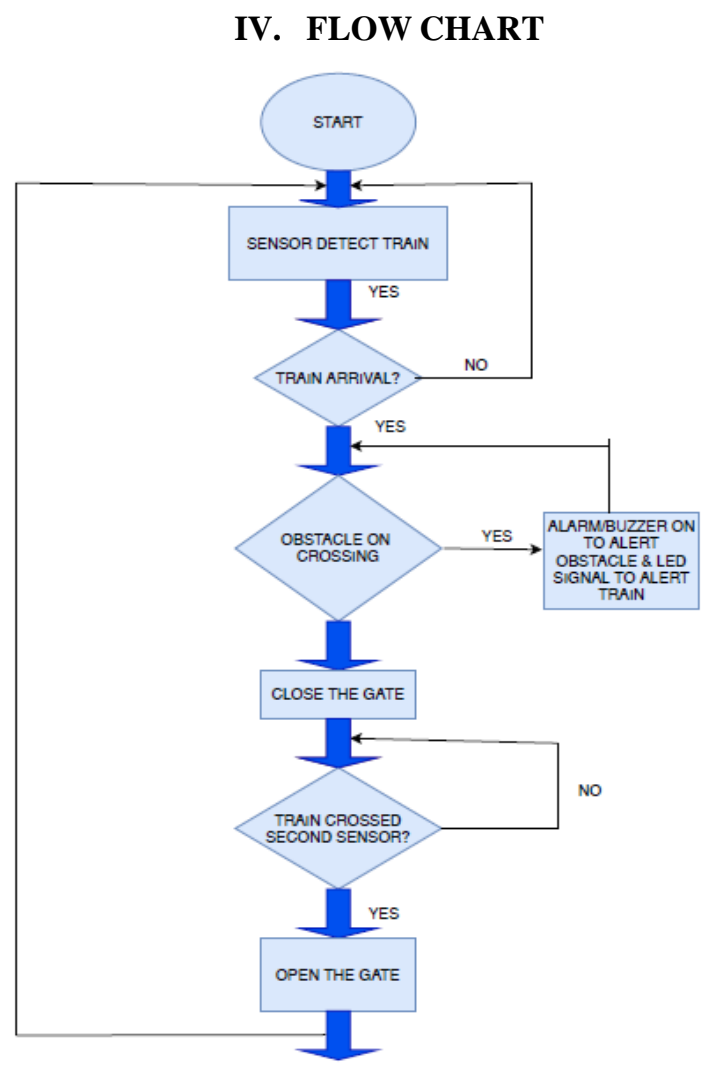

Figure 3: Flow chart showing operation of system

\section{A. Methodology}

In the proposed system, the ultrasonic sensors [6] are used to check the arrival of the train as well as for the departure of the train. Motor driver L293D is used to drive the DC motors for gate closing and opening. Arduino Uno [5] with micro controller ATMega16U2 is used to control all these devices as well as sensors. The ultrasonic sensor which is situated 2 $\mathrm{KM}$ away from the crossing zone detects the arrival of the train and sends the trigger to the Arduino Uno [5] which is having ATMega16U2 microcontroller. Soon after receiving the trigger Arduino Uno will activate the motor driver L293d which power up the DC motor in order to close the gate.

Before closing the gate, Arduino Uno [5] will alert the obstacle at the gate with the help of alarm or buzzer. The ultrasonic sensor [6] situated near the gate will check for any obstacle present near the gate. If any obstacle found near the gate, signal light will be turned on which is situated $2 \mathrm{KM}$ away from the crossing gate. This will alert the train, so that the train can mechanically slow down the speed or if necessary it can also stop. If any obstacles are not present, the gates will be closed and the train can move normally. Once train crosses the second sensor situated at next end, the gate will automatically open. The detailed work flow is shown in figure 4 .

Published By:

Blue Eyes Intelligence Engineering

\& Sciences Publication

(C) Copyright: All rights reserved.

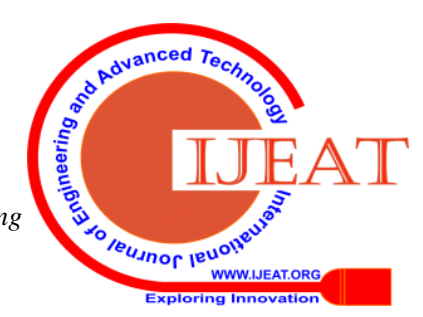




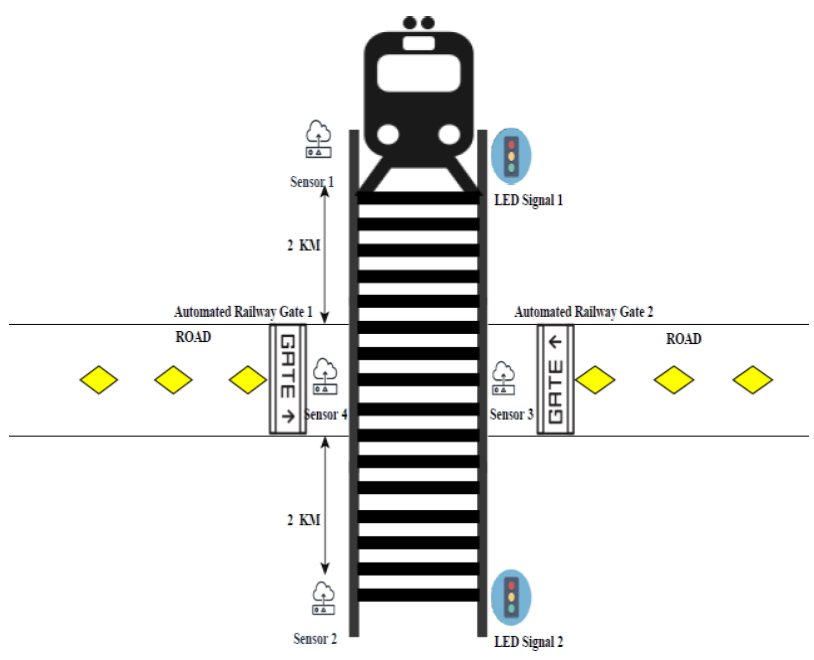

Figure 4: Work Flow

TABLE 1: Devices used and the location of devices

\begin{tabular}{|c|c|c|}
\hline Sl.No & $\begin{array}{l}\text { Devices } \\
\text { Used }\end{array}$ & Location of Devices \\
\hline 1 & $\begin{array}{l}\text { Ultra Sonic } \\
\text { Sensor } 1\end{array}$ & 2 KM away from Gate \\
\hline 2 & $\begin{array}{l}\text { Ultra Sonic } \\
\text { Sensor } 2\end{array}$ & 2 KM away from Gate \\
\hline 3 & $\begin{array}{l}\text { Ultra Sonic } \\
\text { Sensor } 3\end{array}$ & $\begin{array}{l}20 \text { Feet away from track near } \\
\text { Gate }\end{array}$ \\
\hline 4 & $\begin{array}{l}\text { Ultra Sonic } \\
\text { Sensor } 4\end{array}$ & $\begin{array}{l}20 \text { Feet away from other side } \\
\text { of track near Gate }\end{array}$ \\
\hline 5 & LED Signal 1 & $2 \mathrm{Km}$ away from Gate \\
\hline 6 & LED Signal 2 & $\begin{array}{l}2 \text { KM away from other side } \\
\text { of Gate }\end{array}$ \\
\hline 7 & $\begin{array}{l}\text { Automated } \\
\text { railway Gate } \\
1 \\
\end{array}$ & 30 Feet away from track \\
\hline 8 & $\begin{array}{l}\text { Automated } \\
\text { railway Gate } \\
2\end{array}$ & $\begin{array}{l}30 \text { feet away from other side } \\
\text { of track }\end{array}$ \\
\hline
\end{tabular}

\section{A. Micro Controller}

In this system, we are using Arduino Uno [5] with an ATMEGA 16U2 micro controller. The functionalities of microcontroller in this project are listed below:

1 To receive the trigger from the ultra-sonic sensor in order to identify the arrival and departure of the train.

2 To activate the motor driver which in turn power up the DC motor for closing and opening of the railway gates

3 To activate the buzzer/alarm on detecting any obstacle on the railway track

4 To activate the LED signal/light to alert the train about the obstacle on the crossing zone

\section{B. DC Motors}

In the proposed system, two DC motors are used to operate the railway gates both in clockwise (close) as well as anti-clockwise (open) direction. The electric energy will be converted into mechanical energy in this operation.

\section{Sensors: Ultra Sonic Sensor}

The ultrasonic sensors [6] act as an input provider to the Arduino Uno from the end of the railway gate as well as from
$2 \mathrm{Km}$ away from the gate. The ultra-sonic sensor [6] function is to detect the train as well as to detect any obstacle near the gate. The ultra-sonic sensor works based on the emitting sound waves technology.

\section{Motor Driver}

In this proposed system, motor driver L293d is used in order to power up the DC motors which helps in closing and opening of the railway gates. The L293d driver can drive up to two DC motors simultaneously.

\section{E.Arduino IDE}

In this system, Arduino IDE is used as a platform [5]. This platform helps to implement the system using embedded $\mathrm{C}$ language. With the help of Arduino IDE, the code can be dumped into the micro controller. The IDE [5] contains various fields like file, edit, sketch, tools and help. We can even view the result with the help of built-in serial monitor in the IDE.

The table 1 depicts the devices used and the location of devices.

\section{RESULTS}

The results of the proposed work is shown below in table 2 along with the action to be taken

TABLE 2: RESULTS OF THE PROPOSED WORK

\begin{tabular}{|c|c|c|c|}
\hline & SL NO & $\begin{array}{l}\text { ULTRASONIC } \\
\text { SENSOR } \\
\text { STATE }\end{array}$ & ACTION TAKEN \\
\hline & 1 & $\begin{array}{l}\text { SENSOR } \\
\text { ACTIVE }\end{array}$ & $\begin{array}{l}\text { Detects arrival of train } \\
\text { and sends trigger to } \\
\text { Arduino to close the } \\
\text { gates. }\end{array}$ \\
\hline & 2 & $\begin{array}{l}\text { SENSOR } 1 \text { NOT } \\
\text { ACTIVE }\end{array}$ & $\begin{array}{l}\text { No train detected system } \\
\text { will be in idle mode. }\end{array}$ \\
\hline 3 & & $\begin{array}{l}\text { SENSOR } \\
\text { ACTIVE }\end{array}$ & $\begin{array}{l}\text { Detects departure of } \\
\text { train and sends trigger to } \\
\text { Arduino to open the } \\
\text { gates. }\end{array}$ \\
\hline 4 & & $\begin{array}{l}\text { SENSOR } 2 \text { NOT } \\
\text { ACTIVE }\end{array}$ & $\begin{array}{l}\text { No train detected system } \\
\text { will be in idle mode. }\end{array}$ \\
\hline 5 & & $\begin{array}{l}\text { SENSOR } \\
\text { ACTIVE }\end{array}$ & $\begin{array}{l}\text { Obstacle detected near } \\
\text { the gate and sends } \\
\text { trigger to the Arduino to } \\
\text { alert the train by turning } \\
\text { on LED signal. }\end{array}$ \\
\hline
\end{tabular}

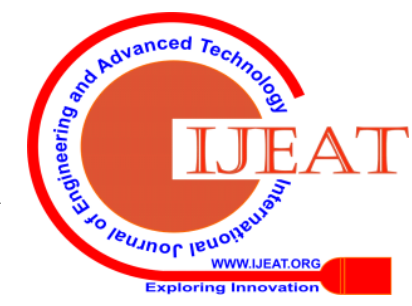


Prevention of Disasters using Automated Railway Crossing System

\begin{tabular}{|l|l|l|}
6 & $\begin{array}{l}\text { SENSOR 3 NOT } \\
\text { ACTIVE }\end{array}$ & $\begin{array}{l}\text { No obstacle detected } \\
\text { near the gate no LED } \\
\text { signal will be turned on. }\end{array}$ \\
\hline 7 & $\begin{array}{l}\text { Obstacle detected near } \\
\text { the other side of gate } \\
\text { and sends trigger to the } \\
\text { Arduino to alert the train } \\
\text { by turning on LED } \\
\text { signal. }\end{array}$ \\
\hline 8 & $\begin{array}{l}\text { SENSOR 4 NOT } \\
\text { ACTIVE }\end{array}$ & $\begin{array}{l}\text { No obstacle detected } \\
\text { near the other side of the } \\
\text { gate no LED signal will } \\
\text { be turned on. }\end{array}$ \\
\hline
\end{tabular}

\section{CONCLUSION}

In India major means for transportation is railway as it is affordable and comfortable and many disasters are happening in railway department due to level crossing and unmanned level crossing. Due to these disasters many humans as well as animals are losing their lives daily. In order to overcome this already there are many prevention measures have been taken from government too but still due to many reason the number of disasters are not coming down. So in this work we are trying to reduce these disasters which are causing due to both manned and unmanned level crossing by auto automating the railway gates. The proposed method has been tested in the college by creating a prototype which is cost efficient, accurate and durable.

\section{REFERENCES}

1. https://factly.in/indian-railway-accidents-statistics-review-last-5-years/

2. Improving Railway Safety with Obstacle Detection and Tracking System using GPS-GSM Model by Nisha S.Punekar, Archana A. Raut , International Journal of Scientific \& Engineering Research, Volume 4, Issue 8, August-2013 288 ISSN 2229-5518

3. Intelligent Railway Crossing Gate Control with High Speed Anti-Collision Alerting System by Sayali R. More VIVA Institute of Technology, Shirgaon, Virar (E) ,Ruchira J. Raut VIVA Institute of Technology, Shirgaon, Virar (E) ,Rasika K. Tandel VIVA Institute of Technology, Shirgaon, Virar (E) ,Snehal D. Yendhe VIVA Institute of Technology, Shirgaon, Virar (E), International Journal of Computer Applications (0975 - 8887) National Conference on Role of Engineers in Nation Building (NCRENB-15)

4. Automation of Railway Gate Control Using Microcontroller by Atul Kumar Dewangan,Meenu Gupta,Pratibha Patel Lecturer, Kirodimal Govt Polytechnic Raigarh,Chhattisgarh,India Diploma Scholar Kirodimal Govt Polytechnic Raigarh,Chhattisgarh,India Diploma Scholar Kirodimal Govt Polytechnic Raigarh,Chhattisgarh,India, International Journal of Engineering Research \& Technology (IJERT) Vol. 1 Issue 3, May - 2012 ISSN: 2278-0181.

5. About Arduino Uno and its working: https://en.wikipedia.org/wiki/Arduino_Uno.

6. About ultrasonic https://www maxbotix.com/articles/how-ul

7. A Review - Automatic Railway Gate Control System by Shubham Shrirao, Dinesh Rojatkar Electronics And Telecommunication Engineering Department, Government College of Engineering Chandrapur, Gondwana University, Gadchiroli, Maharashtra, India. 2016 IJSRSET | Volume 2 | Issue 6 | Print ISSN: 2395-1990 | Online ISSN : 2394-4099 Themed Section: Engineering and Technology.

8. Enhancing security by Automatic Railway Gate Control using Microcontroller and IR Sensor by M. M. Islam1, A. Halder 2 and F. Ahmed 3 Proceedings of 10th Global Engineering, Science and Technology Conference 2-3 January, 2015, BIAM Foundation, Dhaka, Bangladesh, ISBN: 978-1-922069-69-6.
9. Working

of

IR

https://www.elprocus.com/infrared-ir-sensor-circuit-and-working/

\section{AUTHORS PROFILE}

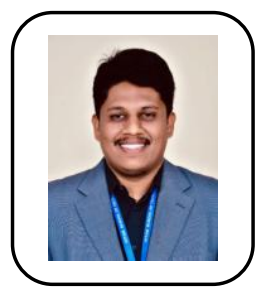

Mr. Yathish.D.P, is currently associated with GITAM (Deemed to be University) as Assistant professor in Computer Science and Engineering Department, GITAM, School of Technology, Bangalore. He has B.Tech degree in Computer Science and Engineering from Channabasaweshwara Institute of Technology, Gubbi,Tumakuru and M.Tech in Computer Science and Engineering from Siddaganga Institute of Technology, Tumakuru. He has professional experience of Three years of teaching. His areas of interest are Compiler Design, Formal Language and Automata Theory, Software Engineering, Artificial Intelligence and applications, Machine Learning, Web Technology and its real time applications, Programing Language and Pragmatics, Operating Systems Robotics, Internet of Things and Sensor Guided Robotics.

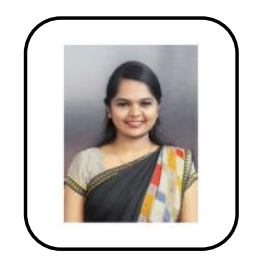

Ms. Nandini S, currently associated with GITAM (Deemed to be University) as Assistant professor in Computer Science and Engineering Department ,GITAM, School of Technology, Bangalore. She has B.Tech degree in Information Science and Engineering from Sapthagiri College of Engineering, Bengaluru and M.Tech in Computer Network and Engineering from Nitte Meenakshi Institute of Technology, Bengaluru. She has professional experience of Three years of teaching. Her areas of interest are Computer Networks, Software Engineering, Artificial Intelligence and applications, Data mining and Data Warehouse, Computer Organization and Architecture, Machine Learning, Real Time Systems, Programing Language and Pragmatics, Operating Systems Robotics, Internet of Things and Sensor Guided Robotics.

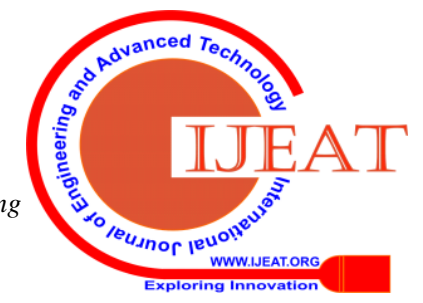

